\title{
Alejandro García Sanjuán, La CONQuista islámica \\ DE LA PENÍNSULA IBÉRICA Y LA TERGIVERSACIÓN DEL pasado. Marcial Pons, Madrid, 2013, 496 PÁGINAS. ISBN: 9788492820931
}

\author{
Luis Molina \\ Escuela de Estudios Árabes - CSIC
}

El progreso de la Ciencia no es siempre lineal. En ocasiones un error de concepto, una mala interpretación de los datos, una elección de objetivos fallida pueden obligar a desandar parte de lo andado y tomar un nuevo camino. Sucede muy a menudo que las teorías equivocadas que dan lugar a tales correcciones de rumbo no son en absoluto estériles: un error puede ser tan clarificador como un éxito, una vía cerrada incrementa las posibilidades de acierto en la nueva que se abre, todas las experiencias, incluso las fallidas, enriquecen nuestro conocimiento.

Pero hay rectificaciones que, por las características del error al que han de ser aplicadas, se convierten en infecundas porque tienen que limitarse a devolver el proceso a su estado inicial, sin que, tras ese viaje de ida y vuelta, nuestros conocimientos hayan avanzado ni un solo paso.

La obra que reseñamos aquí, La conquista islámica de Alejandro García Sanjuán, entra de lleno en esa categoría. El hecho de que sea impecable, demoledora en sus críticas $\mathrm{y}$ de que ningún reparo pueda ponerse a su planteamiento y desarrollo no mitiga la amarga sensación de despilfarro al comprobar que el esfuerzo y el bien hacer del autor han tenido que ser empleados en demoler lo que nunca debió ser construido. Sírvanos de consuelo -no pequeño consuelo- que, gracias a todo esto, contamos por primera vez con un magnífico libro sobre la conquista en el que se reúne todo lo escrito sobre la cuestión desde una perspectiva multidisciplinar.

La empresa en la que García Sanjuán se embarca es la de poner de manifiesto el fraude que representa la corriente "negacionista" que rechaza la historicidad de la conquista musulmana de la Península Ibérica. Surgida a mediados del siglo pasado de la mano de Ignacio Olagüe en su Les arabes n'ont jamais envahi l'Espagne (1969), ha reaparecido con fuerza -bajo presupuestos ideológicos muy distintos, pero manteniendo en líneas generales el aparato argumentativo-, en la obra de Emilio González Ferrín Historia General de al-Andalus (2006). Lo que más llama la atención en el devenir de esta disparatada teoría negacionista es que haya servido a distintos, incluso opuestos, "señores" sin alterarse por ello lo más mínimo. Lo que en Olagüe era exacerbación de la idea rectora de la historiografía nacionalista española en lo referente a al-Andalus, la de minimizar el componente arabomusulmán hasta dejarlo en un leve barniz que no ocultaba la genuina 
hispanidad -cuando no la españolidad- de la "España musulmana", en González Ferrín deviene soporte de una versión muy particular de nacionalismo andalucista. Aunque lo cierto es que el éxito de la teoría de González Ferrín -éxito muy relativo, pero no por ello menos entristecedor- no hay que buscarlo en factores políticos o ideológicos, sino en dos rasgos de los tiempos que nos ha tocado vivir: lo postmoderno y las teorías de la conspiración. Estos dos ingredientes, tan caros a ciertos sectores de la sociedad, son los que dan sabor al guiso de la Historia General de al-Andalus; la postmodernidad se presenta bajo capa de "historiología", evanescente etiqueta que sirve para encubrir el "nada es verdad o es mentira ..." (Historia general, p. 28), o, dicho en otras palabras, la presunción de que es imposible conocer la verdad histórica y que todo intento de objetividad es ilusorio. Cabría esperar entonces que quienes sostienen que la Historia no es una ciencia ni puede aspirar a serlo abandonaran el campo a los pobres incautos que aún creen en la posibilidad de conocer con mayor o menor precisión los hechos del pasado; pero comprobamos -sin mucha sorpresa, cierto es- que lo que de verdad pretenden es concederse a sí mismos una patente de corso para campar a sus anchas, sin molestas ataduras ni requerimientos enojosos, por esos territorios por los que aconsejan a los otros no transitar. En cuanto a la teoría de la conspiración, cuyo mero enunciado garantiza la atención por parte de una categoría muy definida de lectores, el negacionismo sobre la conquista musulmana se ciñe escrupulosamente al patrón más clásico: denuncia la existencia de un grupo cerrado y excluyente de detentadores del poder (en este caso, del poder científico), grupo que actúa de forma planificada contra los heroicos individuos que se enfrentan a las verdades establecidas y al anquilosamiento corporativista de los que no defienden la verdad, sino sus privilegios. Nada que no hayamos oído antes cientos de veces aplicado a cuestiones tan dispares como las vacunas, la llegada del hombre a la Luna, el cambio climático, terapias alternativas, etc. Miles de científicos y técnicos a lo largo del mundo participan de forma concertada en una conspiración para enmascarar la verdad, para lo cual persiguen, marginan e intentan silenciar a los pocos elegidos que han sabido descubrir lo que tan celosamente ocultan los conspiradores.

Desde un punto de vista estrictamente científico, La conquista islámica de Alejandro García Sanjuán constituye una demostración de la absoluta carencia de fundamentos de la teoría negacionista. A lo largo de sus páginas se van sucediendo argumentos de muy distinto tipo y de muy diversas disciplinas que echan por tierra las falacias sobre las que se han construido esas teorías. Aunque el autor no desdeña en modo alguno el testimonio de las fuentes árabes, que analiza con minuciosidad y detenimiento, donde pone un especial énfasis es en las fuentes latinas, pero no sólo en las tradicionales peninsulares como la Chronica Byzantia-arabica y la Crónica mozárabe de 754, sino también en otras de fuera de la Península y de la más variada procedencia: la Historia Ecclesiastica del anglosajón Beda, una carta del evangelizador de Germania, San Bonifacio, la Historia Langobardorum de Pablo Diácono y la anónima crónica franca Chronologia regum gothorum, todas ellas del s. VIII. Junto a ellas García Sanjuán presenta el que él considera el más antiguo testimonio sobre la conquista musulmana conservado, la mención, en el apartado dedicado al papado de Gregorio II del Liber pontificalis, del 
paso de los ejércitos musulmanes a la Península desde Ceuta, la conquista del país y su avance hacia el norte hasta encontrarse con Eudes, duque de Aquitania, que les cerró el paso. Según García Sanjuán, el texto en cuestión debe ser datado entre el 721 y el 731. El otro puntal en el que se sustenta la parte más novedosa y definitiva de la exposición de La conquista islámica es el recurso al registro material, más en concreto a las monedas y a los sellos o precintos. La aportación a la cuestión de la numismática es significativa y elocuente, pero es un campo en el que no se han producido novedades importantes en los últimos tiempos, por lo que resulta bastante enojoso tener que volver a utilizar contra las pretensiones negacionistas los mismos argumentos de siempre, cuando el tema debería haber quedado zanjado mucho tiempo atrás. Distinto es el caso de los precintos de plomo que están siendo sacados a la luz y estudiados en el último decenio. Los inestimables trabajos de Tawfiq Ibrahim en los ejemplares hallados en la Península Ibérica y de Philippe Sénac en el yacimiento de Ruscino, al este de Perpignan, ponen de manifiesto el altísimo valor documental de estas pequeñas piezas de plomo que se utilizaban para precintar e identificar bolsas y sacos que contenían bienes pertenecientes al estado (quinto de botín, impuestos recaudados, pagos por capitulaciones, etc.). Incluso parece probable, según la opinión de Ibrahim (Zona arqueológica, 2011), que uno de esos precintos conserve el más antiguo testimonio del término al-Andalus, puesto que en uno de los sellos a nombre del gobernador al-Hurr (713-715) se aprecia que su nombre se halla contramarcado en una pieza que, por tanto, sería anterior a él, probablemente de época del gobernador 'Abd al- 'Azīz b. Mūsà o incluso del propio Mūsà b. Nușayr. Pero lo que importa retener aquí es que toda la información que estos precintos nos proporcionan, por más que sea fragmentaria y discontinua, coincide perfectamente con lo que sabemos a través de las fuentes escritas. En los años inmediatamente posteriores al 711 existía una administración que gestionaba -empleando la lengua árabe y con inclusión de fórmulas religiosas musulmanas, como la basmala- un mecanismo de dominación fiscal aparentemente muy eficaz.

Lo cierto es que todas las evidencias que se pueden reunir desde fuentes de información distintas de las literarias apuntan en esa misma dirección: lo que se narra en las crónicas es, tanto en líneas generales como en buen número de detalles, esencialmente verídico. No existe ni una sola prueba que demuestre que el relato "tradicional" sobre la conquista musulmana de la Península Ibérica -y sobre sus antecedentes en el Norte de África- sea inexacto, mientras que sí existen, en el otro sentido, abundantes testimonios de todo tipo que confirman dicho relato; más aún, podríamos decir sin caer en la exageración que, cuando aparece un dato relevante para la cuestión en cualquier ámbito del conocimiento, siempre, sin excepción, se demuestra compatible con lo que hemos llamado el "relato tradicional".

Una de esas fuentes de información clamorosamente confirmadoras es el material documental proporcionado por las colecciones de papiros de época islámica. García Sanjuán no lo ha pasado por alto, pero tal vez no le haya concedido la importancia que tienen, pues se trata de un material que aúna la objetividad de las fuentes no literarias con la precisión y la univocidad del documento escrito. Los archivos de documentos adminis- 
trativos contenidos en esos papiros, mayoritariamente árabes y greco-árabes, son, a mi entender, la mejor y más reveladora prueba de que lo que cuentan las crónicas árabes sobre el período de la conquista de al-Andalus es esencialmente cierto. Una de esas colecciones de papiros, la conocida como "papiros de Aphrodito", conserva parte de los escritos enviados por el gobernador de Egipto, Qurra b. Šarīk (709-714), al prefecto de esa ciudad del Alto Nilo (actual Kūm Išqāw, $50 \mathrm{~km}$ al sur de Asyut), Basilius. A pesar de que el interés de Qurra en esas cartas se centra en cuestiones administrativas, fiscales, etc., o sea, pura burocracia rutinaria y tediosa, de vez en cuanto aparecen nombres de personajes conocidos, alusiones a hechos históricos y a fechas señaladas, datos que, volvemos a insistir, se engarzan a la perfección con los acontecimientos históricos relatados por las crónicas árabes.

Aunque redactados en una región alejada de al-Andalus y tratando cuestiones que no tiene la menor relación con ella, los documentos de Qurra son contemporáneos de la conquista de la Península Ibérica y reflejan un estado de cosas que contradice radicalmente la visión que nos ofrece González Ferrín, quien pone en duda la conquista de alAndalus por parte del ejército del estado arabomusulmán porque en el año 711 ni existía estado, ni existía el Islam, ni la lengua árabe se hablaba fuera de Península Arábiga. Los archivos de Aphrodito demuestran que en ese mismo año 711 una administración cuidadosamente organizada redactaba sus documentos en un perfecto árabe -también se utilizaban en Egipto el griego y el copto- y los trufaba de las típicas fórmulas religiosas musulmanas (basmala, "no hay más dios que Allāh", "Muḥammad es su profeta"). Más aún, el conquistador de al-Andalus, Mūsà b. Nușayr -ese personaje cuasi-mitológico para los negacionistas, que llegan a ver en él un trasunto de Moisés, llevando a su pueblo al otro lado de las aguas-, aparece mencionado incidentalmente en uno de estos papiros -en uno de los que se conservan sólo en su versión griega- en relación con un suceso histórico que conocemos bien a través de las crónicas (Sebag, "Les expéditions maritimes arabes du VIII siécle", Les Cahiers de Tunisie, 1960). Cuando se formulan teorías basadas en el artificio indiciario y la retórica alambicada, un solo documento puede bastar a veces para desmontarlas.

Aunque todos nos fijamos más en los aspectos del libro más centrados en la controversia, lo cierto es que en la obra de García Sanjuán no sólo encontramos la refutación de las tesis negacionistas. También se comentan otras visiones de la conquista, desde la catastrofista hasta la edulcorada del "encuentro" y en el último capítulo, “¿Por qué triunfaron los conquistadores?" (359-439) se efectúa un interesante análisis de la aparente facilidad con la que las tropas musulmanas se apoderaron del estado visigodo y se discute la teoría de Eduardo Manzano sobre dos tradiciones cronísticas contrapuestas, la que defendería que al-Andalus se conquistó por la fuerza -sería la doctrina oficial, favorable a las tesis omeyas- y la que sostendría que la conquista se llevó a cabo mediante pactos. García Sanjuán pone en duda -a mi entender, con acierto- la existencia de esas dos corrientes claramente diferenciadas, aunque la cuestión dista de estar totalmente cerrada.

La conquista islámica es un trabajo sólido, que maneja una documentación muy amplia $\mathrm{y}$ variada y que sabe muy bien dónde y cómo atacar las tesis negacionistas. La única 
pega que se le podría poner es la de su estructura y organización, porque en ocasiones parece que ha estado más pendiente de la eficacia polemística que de la claridad expositiva, con el resultado de que hay aspectos que se tocan varias veces en distintos lugares y otros sobre los que nos hubiera gustado que se detuviera más.

Ahora bien, si consideramos que, en realidad, la obra de García Sanjuán y las de los negacionistas a los que replica se mueven en ámbitos intelectuales muy distintos, debemos plantearnos la pregunta de si llevar la discusión a un campo puramente científico no es otorgarle un reconocimiento que el negacionismo ni se merece ni busca. La historiología que, según él, rige el discurso de González Ferrín ¿debe ser combatida con el concurso de lo que, recurriendo a la analogía, podríamos denominar la "historionomía" o la "historiofísica"? No es sencillo responder a esta duda, pero lo cierto es que hay otras formas de enfocar el tema. Una de ellas sería buscar explicaciones en la psicología cognitiva, considerándolo un caso exacerbado de sesgo de confirmación, es decir, la tendencia a tomar en consideración únicamente los datos que favorecen nuestras hipótesis. Una lectura clarificadora sobre esta cuestión sería la obra de M. Shermer, The Believing Brain, donde estudia la propensión innata en el ser humano a adoptar primero las creencias y, posteriormente, buscar las explicaciones o las justificaciones. Pero, claro está, esto sólo podría aplicarse en el caso de que realmente nos halláramos ante el resultado de un sesgo cognitivo, es decir, de un fenómeno psicológico involuntario; de no ser así, la lectura recomendable en este caso sería el trabajo de H. Frankfurt, On Bullshit, ensayo breve, pero extraordinariamente lúcido, del que podemos extraer la caracterización precisa de ese término, bullshit, que no tiene traducción inequívoca al castellano, al menos en esa acepción. Comparándolo con la mentira, Frankfurt llega a la conclusión de que, mientras el mentiroso conoce y reconoce la verdad, pero la sustituye conscientemente por la mentira, el cultivador del bullshit no se preocupa en absoluto de si lo que afirma es verdadero o falso, porque lo único que persigue es, por decirlo en términos muy coloquiales, "pegársela" al lector o "quedarse" con él. Frankfurt comienza su libro: "One of the most salient features of our culture is that there is so much bullshit". Es inevitable estar de acuerdo con él. 
